\title{
O jardim místico do medievo
}

\author{
Maria do Amparo Tavares Maleval \\ Universidade do Estado do Rio de Janeiro
}

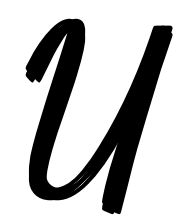

m jardim é comumente entendido como aquela parte da natureza esteticizada, domesticada ou amena, onde se cultivam árvores, flores, plantas ornamentais. Próximo ou componente do habitat humano, diferencia-se da floresta indômita com seus perigos ou do deserto, árido e não menos perigoso.

Na Idade Média ocidental, as ilustrações representam a sua diversidade e maior abrangência; a Grande Enciclopédia Larrousse Cultural, por exemplo, registra que a concepção de jardim no medievo iria

do pomar (quadrangular, murado, com caramanchões de trepadeiras, sebes, árvores frutíferas, flores, fontes e pavilhões) ao bosque irregular, como no parque de Robert d'Artois, em Hesdin (1295-1302), ou o 'jardim paisagem', natural e pitoresco, imaginado no século XV pelo rei René em Anjou e depois na Provença. ${ }^{1}$

A construção de um jardim medieval não levaria em conta apenas a estética, que impera em nossos dias; incluía, junto às flores, trepadeiras e outros adornos, árvores frutíferas - hoje via de regra restritas ao pomar - e outras plantas não meramente decorativas, como as ervas medicinais - hoje características das hortas. Configurava-se, dessa forma, como um espaço não apenas aprazível por sua beleza, mas um lugar de reconforto,

${ }^{1}$ LARROUSSE, 1998, p. 3318. 
onde se podia matar a sede e até mesmo a fome; era também um lugar de cura, denominado por horto, vergel e bosco nas obras que focalizaremos.

Importa observar que na Alta Idade Média latina predominou uma concepção simbólica do mundo alimentada pela patrística e pela filosofia, uma visão religiosa do cosmo, que apreende "no mundo criado um sistema de símbolos, uma linguagem figurada de Deus, que recorda aos homens verdades de ordem ética e religiosa, segundo um estreito paralelismo com a Sagrada Escritura". ${ }^{2}$ Bastante ilustrativa desse entendimento é a recomendação de Santo Agostinho, destacada por Tullio Gregory em seu estudo sobre a natureza na Idade Média: " "que a página divina seja (...) o livro que permite ouvir falar destas coisas, e que a terra seja (...) o livro que permite vê-las".

Sendo a natureza considerada um dos dois Livros divinos - Hugo de Saint-Victor, em De tribus diebus, a ela se refere como um livro 'escrito pelo dedo de Deus'- poderia ser interpretada atinando-se para os mesmos sentidos buscados na exegese da Bíblia - literal, alegórico, tropológico e, o que nos interessa particularmente por agora, anagógico. Assim,

os significados da Bíblia seriam também os do "livro das criaturas", e o discurso "sobre a natureza" (de natura rerum) submeteria os seres criados a todas as transposições simbólicas, alegóricas, morais e tipológicas possíveis, porque, tomados no seu conjunto, eles constituiriam, segundo Pedro Damiano, um "símbolo sagrado [sacramentarum] da inteligência espiritual". ${ }^{4}$

${ }^{2}$ GREGORY, 2002, p. 263.

${ }^{3}$ AGOSTINHO, Enarrationes in psalmos, XLV, 7; citação de GREGORY, 2002, p. 263.

${ }^{4}$ GREGORY, 2002, p. 263. 
Mesmo com a entrada em cena da física greco-árabe nos séculos XII-XIII, esse cosmo "manter-se-á um elemento essencial da cultura e da mentalidade medievais", 5 endossado pelo franciscanismo inclusive no seu combate aos cátaros, que abominavam a natureza. Por exemplo, os sermões de Santo Antônio de Lisboa dão conta dessa opção, ao lançarem mão de exempla dos Bestiários com o intuito de converter os hereges ou de manter na fé os cristãos. ${ }^{6}$

Enfim, na literatura e na arte medieval encontraremos representações várias do jardim ou do bosque aprazível, com suas flores, frutos, fontes e ervas medicinais. São, para além do locus amoenus de prazeres materiais, ora ressonâncias do Jardim do Éden de que foram expulsos Adão e Eva a partir da transgressão cometida, ora vislumbres do Paraíso celestial ou propagandas de como merecê-lo e consolo nesse mundo de privações.

\section{Jardins místicos na prosa portuguesa tardomedieva}

Trataremos a seguir de três obras da Baixa Idade Média, relacionadas desde os títulos com estas últimas representações e como tal destinadas à edificação espiritual: Horto do Esposo, Bosco deleitoso e Vergel de consolação. Lembramos que o fato de terem sido escritas não em latim, mas em português, tornandoas dessa forma mais acessíveis à compreensão de um maior número de receptores, já as colocava em sintonia com o

${ }^{5}$ GREGORY, 2002, p. 265.

${ }^{6}$ Cf., a propósito, a dissertação de Mestrado intitulada "Simbolismo animal: os sermões de Santo António de Lisboa e o bestiário medieval", elaborada por Glicia Silva Campos sob minha orientação no Programa de Pós-Graduação em Letras da UERJ, defendida em 24 de março de 2010. 
processo de democratização da Igreja, que se vinha operando para fazer frente às heresias. Nesse sentido, também a utilização de exemplos na prédica e na literatura moralizadora, aliás profusamente abundantes no Horto do Esposo, representa(ou) um eficaz meio de vulgarização dos ensinamentos, ligando-se, por isso, à renovação das estratégias de pregação promovidas pelas Ordens Mendicantes.

\section{Vergel de consolação}

Vergel de consolação, manuscrito em português medieval, encontra-se no códice alcobacense CCXLIV /211, arquivado na BNL, ocupando-lhe as páginas 8-73. Segundo Mário Martins, 7 é a "versão medievo-portuguesa do Vergel de Consolación, atribuído a frei Jacobo de Benavente, frade dominicano do século XIV" - o que não resolve de todo a questão da autoria, conforme demonstrou Albino de Bem Veiga, ${ }^{8}$ mas permite-nos situá-lo cronologicamente, dado que as duas obras mais se aproximam que se afastam.

No Prólogo, que antecede a uma espécie de sumário da obra, temos a explicação do título:

...porque en esta obra acharõ geeral avondança de auctoridades de sanctos, e d'alguu[n]s sabedores, que daram odor de gram plazer, assi como flores ajuntadas de desvayradas maneyras e de desvayrados lugares.

E portanto esta obra he chamada Virgeu de Plazer e de Consolaçom, porque bem assi como no virgeu son achadas flores e fructos de desvayradas maneyras, assy en esta obra son achadas muitas e desvayradas auctoridades, que dam plazer

7 MARTINS, 1949, p. 69.

${ }^{8}$ VEIGA, 1959, p. XI. 
maravilhosamente ao coraçom daquel que as cõ vootande leer ou ouvir. ${ }^{9}$

Portanto, os ensinamentos e exemplos dos sábios e santos representam as flores e frutos desse jardim, constituído pela obra, destinada ao consolo e ensinamento do cristão nesse sofrido e precário mundo terreno.

Divide-se em cinco partes e 78 capítulos, tratando as duas primeiras dos pecados a serem evitados e as três últimas das virtudes a serem praticadas para o alcance do Paraíso celestial. A primeira parte fala dos pecados capitais - soberba, inveja, sanha, acídia (negligência e preguiça), avareza, gula (gargantuice e bevedice), luxúria. A segunda, após inicial definição de pecado, arrola pecados como a descrença, a arrogância, a ambição, a ingratidão, a hipocrisia, a falsidade, a vanglória, o mau juízo, a acusação injusta, a maledicência, a discussão insana, a bajulação, a tagarelice, a mentira, a malquerença, a demonolatria, a sedução, a heresia, etc. A terceira fala das seguintes virtudes: fé, esperança, caridade, sabedoria, fortaleza, temperança, justiça. A quarta, das demais virtudes, como: humildade, paciência, temor de Deus, amor a Deus, amor ao próximo, compaixão, discernimento sobre o que deve ser repreendido e castigado, caridade, jejum, discrição, compunção ou contrição. A quinta, de outras virtudes, na verdade práticas religiosas, destinadas à salvação da alma, como: confissão, penitência, conhecimento dos livros sagrados, oração, contemplação, louvor a Deus, perseverança, pobreza, obediência, castidade, virgindade, afastamento das mulheres, honestidade, vergonha, louvores marianos, amizade, grandeza, juízos destemidos, louvor da religião; além de conceituações e reflexões sobre prelados, clérigos pregadores, predestinados, condições do homem, Juízo Final, penas infernais, culminando

${ }^{9}$ VERGEL, 1959, p. 3. 
com o "louvor dos santos que estão no paraíso, e do galardão que hão de haver". ${ }^{10}$

Sobre o Paraíso, no capítulo final da obra, considera o narrador, respaldando-se em São Gregório, ser impossível falar e compreender de forma completa as suas beatitudes. E evoca autoridades que buscaram descrevê-lo, como o próprio São Gregório, São Bernardo, Santo Ambrósio, Boécio e principalmente Santo Agostinho, para quem

ali he sempre dia em que non ha nocte, e comprimento de gloria verdadeyra, fartura perduravil; aly nõ há termo d'alegria, $n e[m]$ falecimento de claridade, ne[m] avondança de nojo, mais gloriosa e verdadeyra fartura, e muy sancto ajuntamento, e desejado comer, hu nu[n]ca pode seer ne[n]huu[m] pesar, ne[m] mjngua ne[m] nojo, mas muy doce morada do sancto parayso. E porende, jrmãaos, trabalhemos muyto pera hyr a aquel logar tan seguro, e logar muy doce...11

As palavras finais da citação, referindo-se ao modo trabalhoso de se conseguir o Paraíso, justificam a escrita do livro, na verdade um manual, apoiado em autoridades, para o conhecimento dos pecados ou vícios que afastam da salvação e das virtudes que devem guiar os passos dos que almejam serem recebidos na Casa do Senhor e usufruírem do seu Jardim.

\section{Horto do Esposo}

Horto do Esposo é obra que procede igualmente do Mosteiro de Santa Maria de Alcobaça, na transição do século XIV para o século $\mathrm{XV}$, também arquivados os seus manuscritos, em

\footnotetext{
${ }^{10}$ VERGEL, 1959, p. 6; modernizamos a grafia.

${ }^{11}$ VERGEL, 1959, p. 124. Dada a dificuldade de colocação do til sobre as vogais e e $u$, optamos por, diferentemente da edição utilizada, usar $\mathrm{m}$ ou $\mathrm{n}$ entre colchetes, como índices de nasalidade.
} 
número de dois, na BNL; e outros fragmentos, na TT. Trata-se, ao que tudo indica, de obra anônima escrita à época da Revolução portuguesa de 1383-1385, à qual faz referência, ou à do genial cronista Fernão Lopes, e que guarda estreito parentesco com a também anônima Bosco deleitoso, posteriormente publicada, sendo-lhes frequentemente apontada uma comum influência, de Petrarca.

Manual de doutrinação religiosa, apresenta tendências vincadamente ascetas, em que as reflexões moralizantes aparecem via de regra ilustradas por numerosos exempla. ${ }^{12}$ Estes, certamente muito contribuíam para a persuasão dos leitores-ouvintes, para a compreensão, aceitação e assimilação da 'verdade' das abstrações apresentadas, muitas das quais acerca do gênero feminino, respaldadas em autoridades da história bíblica e greco-romana profundamente misóginas.

Divide-se em quatro partes ou livros, sendo que o segundo deles focaliza o "Paraíso terreal", ao qual retornaremos adiante.

${ }^{12}$ Como observa o historiador Jacques Le Goff, o exemplum medieval consistia numa história "breve, fácil de ser lembrada", "um pequeno talismã que, se for bem compreendido e utilizado, deve trazer a salvação", fazendo-se desta forma "a chave para o Paraíso" (LE GOFF, 1989, p. 13). Portanto, a brevitas, aliada a outros recursos impressivos, como a visualização (à qual reagia mais que a tudo o homem medieval), permitida pelas cenas evocadas, propiciariam a memorização da historieta e da lição edificante por ela veiculada. E a citação de autorictas, sobretudo de autores e personagens eméritos do mundo greco-romano e judaico-cristão, davam força de verdade incontestável às idéias que se desejava fazer aceitas. A arte doutrinária constituía, dessa forma, um processo claramente intertextual, situando-se numa perspectiva historicizante, nestes seus constantes apelos à tradição, sacra e profana - aqui se incluindo a contribuição folclórica e, muitas vezes através desta, oriental. 
Já no Prólogo do Livro I, apresenta-se o objetivo da obra, dedicada "aa honra e louvor de nosso Senhor Jhesu Christo, flor mui preciosa e fruito mui doce de todalas almas". ${ }^{13} \mathrm{E}$ o autor se refere aos receptores - os simples - para os quais foi composta, com o fito de proporcionar-lhes ao mesmo tempo prazer e proveito espiritual: "pera proveito e spiritual dilectaçom de todolos simplezes, fiees de Jhesu Christo". ${ }^{14}$ Procede o anônimo autor também à explicação das metáforas do título, a começar por Esposo "Jhesu Christo, que é esposo de toda fiel alma"15 -, e, a partir daí, para o primeiro termo, Horto. Este termo, aliás, fora bastante corrente na Europa medieval, até o século XVI, o que em Portugal se comprova também na tradução quatrocentista da obra anteriormente referida, Vergel de Consolação.

Revela-se a relação orto/livro, uma vez que neste

assi como em no orto ha hervas e arvores e fruitos e flores e especias de muitas maneiras pera delectaçom e mantimeto e meezinha dos corpos, bem assi em este livro som conteudas muitas cousas pera mantimento e deleitaçom e meezinha e consolaçom das almas [dos homees] de qualquer condiçom. ${ }^{16}$

Reafirma-se, portanto, a sua finalidade de deleitação e proveito espiritual, proporcionando ao mesmo tempo mantimento e remédio para as almas.

No capítulo segundo, o seu Prólogo se refere à semelhança da Santa Escritura com o horto do "Paraíso terreal", pois como este

ela é mui fremosamente apostada com maravilhosos enxertos, e mui graciosamente afeitada com mui graciosas plantas, é

\footnotetext{
${ }^{13}$ HORTO DO ESPOSO, 2007, p. 3.

${ }^{14}$ HORTO DO ESPOSO, 2007, p. 3.

${ }^{15}$ HORTO DO ESPOSO, 2007, p. 5.

${ }^{16}$ HORTO DO ESPOSO, 2007, p. 5.
} 
aprovada mui compridamente com especias de mui bõo odor, $e$ com flores mui resplandecentes é mui deleitosamente cheirada, e com fructos mui dilicados é mui avondosamente deleitosa, e com mui temperados orvalhos é mui blandamente regada, é mui saudavelmente abalada com ventos mui mansos de grande temperança, e com mui deleitosos cantares d'aves é mui docemente ressoada, e com mui limpos rios é mui abastosamente circundada, e com mui fortes sebes é mui seguramente guardada, e com rebanhos mui previstos é com grande vigilia governada. ${ }^{17}$

Após a descrição do Paraíso terrestre no primeiro capítulo, interditado aos espíritos malignos e à geração humana em decorrência do pecado de Adão e Eva, os demais treze capítulos que compõem o livro desenvolvem a comparação entre os elementos do Paraíso e das Escrituras: enxertos, plantas, espécies aromáticas, flores, árvores, frutos, orvalhos, ervas, ventos, cantares das aves, rios, muro e guardadores. Por exemplo, as plantas da Santa Escritura são duas: "a plantaçom da egreja militante", isto é, a reunião dos fiéis na presente vida, e a da "egreja triunfante" - os santos na glória celestial;18 as espécies aromáticas são "o encenço da devaçam e a mirra da mortificaçam da carne e o cinamomom da renembrança da morte e o balsamo da perseverança"; 19 etc. Todas essas comparações são atestadas por exemplos, historietas curtas que facilitam o entendimento da lição.

A obra é dedicada, de forma particular, ao comprazimento e deleitação de uma certa "irmã", na sua velhice. Não se trata, pois, de um livro que da sua recepção exclua as "filhas de Eva", mas que, pelo contrário, dirigir-se-ia a uma monja, para seu consolo. No entanto, os exempla, em sua maioria, se

\footnotetext{
${ }^{17}$ HORTO DO ESPOSO, 2007, p. 17.

${ }^{18}$ HORTO DO ESPOSO, 2007, p. 20.

${ }^{19}$ HORTO DO ESPOSO, 2007, p. 21-22.
} 
destinam a abominar o gênero feminino, ${ }^{20}$ sendo poucas as santas de que trata: ${ }^{21}$ são as mulheres as principais ervas daninhas desse horto, o que se respalda também na voz das autoridades invocadas.

Dentre os seus ensinamentos, estabelece o louvor aos castrados e às mulheres estéreis ou insensíveis ao sexo, apresentando como preferíveis os filhos espirituais aos carnais, que podem proporcionar danos aos genitores, prendendo-os às 'vanidades' do mundo material. E aconselha, para a salvação da mulher (principalmente, mas não só), o isolamento, abraçado pela Madalena,; ${ }^{22}$ jejum, que leva à cura dos males corporais, à contemplação e à consolação espiritual, à sanidade/santidade.

${ }^{20}$ Desenvolvemos essa questão em estudo anterior, intitulado "Mulheres exemplares no Orto do Esposo" (MALEVAL, 2005, p. 63-80).

${ }^{21}$ Apresenta uma infinidade de más mulheres: as endemoniadas (ORTO DO ESPOSO, 1956, p. 11) e as que solicitam intervenção do diabo para procriarem (ORTO DO ESPOSO, 1956, p. 13); as sedutoras artistas, que, segundo o próprio diabo, "som as nossas armas e nossos laços, ca per estas cousas que trage e per seus cantares e danças fez a nos gaanhar muytas almas" (ORTO DO ESPOSO, 1956, p. 161). Mas chama-se a atenção sobretudo para as vingativas e astuciosas. No primeiro caso, está a mulher de Alexandre, que seduz Aristóteles por haver aconselhado ao marido não procurá-la amiudemente (ORTO DO ESPOSO, 1956, p. 153).

Evidentemente que nas condenadas "deleitações corporais", os homens privilegiam ... a companhia das mulheres. Daí serem amaldiçoadas pelos Padres da Igreja, como Santo Ambrósio, São Jerônimo e Santo Agostinho, e por outras autoridades, da Antiguidade Greco-latina, como Pitágoras, Catão, Cícero, invocadas para sustento de tal ideologia.

${ }^{22}$ HORTO DO ESPOSO, 2007, p. 315. 
Ao contrário, a super-estima pelo corpo, o orgulho e a vaidade são radicalmente condenados, pois conduzem à perdição.

Enfim, com o respaldo de autoridades da Igreja e do universo judaico-greco-romano, o Horto do Esposo se coloca em sintonia, de forma mais fecunda e incisiva que as demais obras em estudo, com a onda de misoginia que então se exacerbava na Europa, dando origem à aterradora caça às bruxas, que se firmaria na ultrapassagem do século XIV para o século $X V{ }^{23}$ mesma época em que a obra fora escrita.

Por outro lado, documenta, igualmente, o culto mariano - Maria é, desde o Prólogo, apresentada como a "rosa singular e estremada da celestial deleitaçom...". ${ }^{24}$ Esse culto, como sabemos, se impusera desde o século XII ascencionalmente, substituindo inclusive o culto da dama pelos trovadores occitanos.

\section{Bosco deleitoso}

Bosco deleitoso foi provavelmente escrito em fins do século $\mathrm{XIV}$, inícios do XV, segundo Leite de Vasconcelos a partir do exame das suas características linguísticas; ${ }^{25}$ mas foi impresso em 1515, Lisboa, por Hermão Campos, e dedicado à franciscana rainha D. Leonor, viúva de D. João II e irmã de D. Manuel, que mandou imprimir o livro, "como aquela que sempre foi enclinada a toda virtude e bem-fazer, zelosa grandemente de sua salvaçam e de toda alma cristãa". ${ }^{26}$

${ }^{23}$ Disto dá prova a elaboração de manuais para a caça às bruxas, como o de autoria dos inquisidores Kremer e Sprenger, intitulado Malleus maleficarum (KREMER; SPRENGER, 1991).

${ }^{24}$ HORTO DO ESPOSO, 2007, p. 3.

${ }^{25}$ MAGNE, 1950, p. II.

${ }^{26}$ BOSCO, 1950, p. 1. 
O seu título se explica levando-se em conta que

Assi como o boosco é lugar apartado das gentes e áspero e êrmo, e vivem enele animálias espantosas, assi eneste livro se conteem muitos falamentos da vida solitária e muitos dizeres, ásperos e de grande temor pera os pecadores duros de converter. ${ }^{27}$

Portanto, o bosque não se configuraria como um locus amoenus. Mas, se comparado à floresta, daria melhores condições para a prática do ascetismo, conforme defende João David Pinto Correia: ${ }^{28}$

Segundo as concepções medievais, o 'bosque', aliás como o 'castelo' e o 'vergel', porque espaço considerado bem delimitado, constituía o mais adequado cenário para uma realização espiritual como a que se pretendia com o aproveitamento da solitude, em contraste com a 'floresta' que representava não só o perigo, o roubo e a violação, como sobretudo a desordem, o desassossego e a instabilidade. $^{29}$

O próprio autor anônimo da obra reconhece o lado positivo desse espaço, de resto descrito com base em lugar comum da literatura pastoril:

Outrossi, em no boosco há muitas ervas e árvores e froles de muitas maneiras, que som vertuosas pera a saúde dos corpose graciosas aos sentidos corporaaes. E outrossi há $i$ fontes e rios de limpas e craras águas, e aves, que cantam docemente, e caças pera mantimento do corpo". ${ }^{30}$

${ }^{27}$ BOSCO, 1950, p. 1.

${ }^{28}$ CORREIA, 1993, p. 107.

${ }^{29}$ CORREIA, 1993, p. 107.

${ }^{30}$ BOSCO, 1950, p. 1. 
Dessa forma, acentuam-se as dificuldades desse bosque, que não é o Paraíso celestial, mas que fornece elementos para o seu alcance. Assim como ele, é o livro, que

conteem enxempros e falamentos e doutrinas muito proveitosas e de grande consolaçom e mui craras pera a saúde das almas e pera mantiimento espritual dos corações dos servos de Nosso Senhor, e pera aquêles que estam fora do caminho da celestrial cidade do paraíso poderem tornar a carreira e ao estado de salvaçom e poderem alcançar aquela maior perfeiçom, que o homem pode haver enesta presente vida, e haver o maior prazer e aquela maior dolçura e consolaçom espritual, que a alma pode receber enquanto está em no corpo e, depois desta vida, haver e possuir a grória perdurávil, tomando enxempro de uu[m] homem pecador, que todo êsto encalçou em vida apartada e solitária dos negócios do mundo, segundo ele reconta de si meesmo... ${ }^{31}$

A qualificação 'deleitoso' remete, pois, para o plano espiritual, sendo a obra "respeitante ao gozo da alma e a aspectos ascéticos e místicos próprios de quem optou pela vida solitária". 32

Retoma o De vita solitaria de Petrarca, escrito entre 1346 e 1356, que reproduz, com pequenas falhas e interpolações, do capítulo XVI ao CXVII, conforme observara Augusto Magne que atenta para o seguinte fato: não gratuitamente entra em cena, no capítulo XVI, um novo narrador, um nobre solitário de nome D. Francisco (primeiro nome de Petrarca), que desaparece no CXVIII. Magne ajuizara que, no entanto, o conjunto da obra, com 153 capítulos, é "mais espiritual, menos erudito, mais poético", "inspirando-se em ascetismo mais profundamente

${ }^{31}$ BOSCO, 1950, p. 2.

${ }^{32}$ CORREIA, 1993, p. 107. 
cristão" que o modelo. ${ }^{33}$ Com Mário Martins, ${ }^{34}$ conclui-se: a obra se caracteriza pelo "humanismo religioso, bucolismo, apologia dos livros e da vida mística".

A narrativa em primeira pessoa apresenta o personagemnarrador como um mesquinho pecador, "desterrado do paraíso terreal das mui doces deleitações, polo pecado dos primeiros padres, $e$ lançado em no vale da mezquindade deste mundo". ${ }^{35}$ Atormentado pelas trevas infernais provocadas pela vida pecaminosa, luxuriosa, que levava, buscava "amiúde andar e espaçar per uu[m] campo mui fremoso, comprido de muitas ervas e froles de boõ odor", não conseguindo nem mesmo aí livrar-se das muito escuras trevas que o cercavam "em-derredor" e "dentro", na sua consciência". ${ }^{36}$ Mas acerca dali "estava uu[m] boosco mui espesso de árvores mui fremosas, em que criavom muitas aves, que cantavom mui docemente". ${ }^{37}$ Neste espaço, invocando ao Senhor pela libertação, as aves lhe respondem que a Graça o libertaria. Porque as aves, como lhe explica o anjo resplandecente que então consegue visualizar, são "os santos doutores que ordenarom a santa escritura", e eles confortam, admoestam, ameaçam, e apontam para a contrição e penitência como meio de alcance da misericórdia. Porque, diz-lhe o Anjo da Guarda,

a tua alma, que é seca, vaa-se trigosamente a esta fonte, e a tua mizquindade recorra-se com todo cuidado a esta alteza da misericórdia da beenta Virgem, ca ela escança vinho de consolaçom pera os tristes e desconsolados. ${ }^{38}$

\footnotetext{
${ }^{33}$ MAGNE, 1950, p. v.

${ }^{34}$ MARTINS, 1973, p. 116.

${ }^{35}$ BOSCO, 1950, p. 3.

${ }^{36}$ BOSCO,1950, p. 4.

37 BOSCO,1950, p. 4.

${ }^{38}$ BOSCO, 1950, p. 6.
} 
A partir de então, o penitente, guiado pelo Anjo da Guarda, dialoga com santos, padres e doutores da Igreja, filósofos como Cícero e Sêneca e outras personagens emblemáticas em sua caminhada rumo ao ascetismo, à elevação espiritual. Inicia-se pela convivência com as virtudes alegorizadas do Horto -Justiça, Temperança, Fortaleza, Prudência, Fé, Esperança, Caridade, Misericórdia, Ciência da Sagrada Escritura -, que o admoestam veementemente pelos pecados cometidos e o exortam à purificação. Assim, a primeira parte da obra trata "Do horto aprazível, em companhia das virtudes". A segunda parte apresenta o "Contraste entre a vida do morador da cidade, ocupado em negócios, e a do solitário assessegado". A terceira, a "Defesa da vida solitária". A quarta, "Mais argumentos em defesa da vida solitária". A quinta, "Exemplos de solitários ilustres". A sexta, "Novos argumentos em defesa da vida solitária - O boosco nevoso" (da penitência). A sétima, "O gracioso campo" (da ciência divina). A oitava, "O alto monte", coroado pela Morada do Senhor.

Apresenta, pois, a caminhada ascensional do pecador arrependido para a contemplação, para o cume do 'Alto monte', onde se encontra o Esposo - final totalmente original em relação à obra de Petrarca. E a sua alma, finalmente purificada, se separa do corpo, sendo então recebida e coroada no Reino Celestial. Porque, como acentua o discurso atribuído a Jesus Cristo, "as flores das tuas obras apareceron ante mi e derom boõ odor de virtudes em na terra celistrial". Daí o convite subsequente: "Levanta-se trigosamente, amiga minha, fremosa minha, poomba minha, esposa minha, e vem-te, ca eu cobiço a tua fremosura" ${ }^{39}$ Dessas qualificações, as duas primeiras amiga e fremosa - tornaram-se lugar-comum na lírica profana

${ }^{39}$ BOSCO, 1950, p. 339. 
medieval galego-portuguesa, nas cantigas de amigo, como as de Pero Meogo que adiante analisaremos.

\section{O jardim místico dos poetas}

Importa por agora salientar que do jardim espiritual os poetas medievais nos legaram muitas representações. Para só citarmos alguns dos numerosíssimos exemplos, nele Maria é a "rosa das rosas e fror das frores" para Afonso X no século XIII. ${ }^{40}$ Para o Mestre André Dias, no século XV, é a "muyto clara e lympa fontana", "rosa e fructuosa olyva", "muyto fremoso lilio", 41 "rosa do parayso", 42 "rosa pareçente". ${ }^{43}$ Da mesma forma, para este poeta Jesus Cristo é o "fremoso lilyo, branco e vermelho / nado em este mundo", 44 é a "Flor de Nazare", 45 é o "fruyto saboroso", 46 a "flor do orto". ${ }^{47}$

Mas não apenas os poetas que explicitamente invocam os santos, a divindade, o Paraíso, nos apresentam esse lado místico do jardim medieval. Em poesias que, à primeira vista, se dedicam ao amor entre homem e mulher, também aí poderia ser entrevisto, apelando-se para os vários sentidos que, a exemplo da Bíblia, os textos medievais, mesmo profanos, possuiriam. Isto permitiria exegeses como a que eminentes

\footnotetext{
40 AFONSO X, 1981, p. 133.

${ }^{41}$ DIAS, 1951, p. 44.

${ }^{42}$ DIAS, 1951, p. 114.

${ }^{43}$ DIAS, 1951, p. 121.

${ }^{44}$ DIAS, 1951, p. 92.

45 DIAS, 1951, p. 94.

${ }^{46}$ DIAS, 1951, p. 213.

${ }^{47}$ DIAS, 1951, p. 227.
} 
medievalistas, como Celso Cunha, ${ }^{48}$ legaram-nos sobre as 'cantigas de fonte' atribuídas ao jogral galego Pero Meogo, do século XIII.

Nessas cantigas, sobressaem as imagens da fonte e do cervo, como podemos ver na que a seguir transcreveremos, com base na edição crítica efetivada por Leodegário Azevedo Filho: ${ }^{49}$

[Levou-s'a louçana,] levou-s'a velida:

vay lavar cabelos, na fontana fria.

Leda dos amores, dos amores leda.

[Levou-s'a velida,] levou-s'a louçana:

vay lavar cabelos, na fria fontana.

Leda dos amores, dos amores leda.

Vay lavar cabelos, na fontana fria:

passou seu amigo, que lhi bem queria.

Leda dos amores, dos amores leda.

Vay lavar cabelos, na fria fontana:

passa seu amigo, que a muyt'amava.

Leda dos amores, dos amores leda.

Passa seu amigo, que lhi bem queria:

o cervo do monte a áugua volvia.

Leda dos amores, dos amores leda.

Passa seu amigo, que a muyt'amava:

o cervo do monte volvia a áugua.

Leda dos amores, dos amores leda.

Como sabemos, o cervo representa o namorado ou amigo - o que, como observa Celso Cunha, não era um sentido

${ }^{48}$ CUNHA, 1985, p. 17-31.

${ }^{49}$ AZEVEDO FILHO, 1974, p. 59. 
alegórico, mas literal para a época, "pois era o esperado pelos leitores e ouvintes" de então. ${ }^{50}$ Símbolo fálico, "pertence à mais típica herança do paganismo hispânico", conforme assinalara Eugenio Asensio;, ${ }^{51}$ Filgueira Valverde ${ }^{52}$ aponta-lhe a relação com a sede de Deus no Salmo 41 (42, na edição da Bíblia que adotamos), que diz: "Como a corça bramindo / por águas correntes, / assim minha alma está bramindo / por ti, ó meu Deus!". ${ }^{53}$ E Luciana Stegagno Picchio ${ }^{54}$ destaca a herança da poesia hebraica, procedente do Velho Testamento e das carjas moçárabes, onde o cervo também se identificava com o amante. Tais indicações já haviam sido levadas em conta por Méndez Ferrín, ${ }^{55}$ buscando chegar às origens desse símbolo erótico.

Cunha ${ }^{56}$ acrescenta, às fontes "desse motivo literário e iconográfico tão vulgarizado na Idade Média eno Renascimento", uma que considera fundamental: o episódio da Eneida ${ }^{57}$ no qual Virgílio

compara o ardor da paixão amorosa de Dido a vagar enlouquecida pelas ruas de Cartago ao sofrimento da cerva, ferida de morte pela flecha do pastor, a correr desorientada através do bosque de Creta. ${ }^{58}$

${ }^{50}$ CUNHA, 1985, p. 28.

51 ASENSIO, 1970, p. 52.

${ }^{52}$ VALVERDE, 1927.

${ }^{53}$ BÍBLIA, [1981], p. 690.

${ }^{54}$ PICCHIO, 1973, p. 252.

${ }^{55}$ MÉNDEZ FERRÍN, 1966.

${ }^{56}$ CUNHA, 1985, p. 29.

${ }^{57}$ ENEIDA, IV, 66-73.

${ }^{58}$ CUNHA, 1985, p. 29. 
Na representação trovadoresca, de Pero Meogo, temos esse mesmo motivo do "cervo ferido", atingido pelo amor:

- Tal vay o meu amigo, com amor que lh'eu dey, come cervo ferido de monteyro d'el-Rey.

Tal vay o meu amigo, madre, com meu amor, come cervo ferido de monteyro mayor.

E, se el vay ferido, irá morrer al mar; si fará meu amigo, se eu d'el non pensar.

- E guardade-vos, filha, ca já m'eu atal vi que se fez coitado, por guaanhar de min.

E guardade-vos, filha, cá já m'eu vi atal que se fez coitado, por de min guaanhar. ${ }^{59}$

Frisa Celso Cunha que esse "motivo do cervo flechado que busca a fonte onde possa dessedentar-se ou morrer é um dos preferidos da iconografia medieval ${ }^{\prime \prime},{ }^{60}$ onde, acrescenta, frequentemente é representado "com uma erva na boca - vã esperança de cura, pois como se diz na costumeira legenda malum immedicabile, "mal incurável", porque mal de amante".

Observe-se, na cantiga acima, que a fala da mãe da jovem enamorada se atém ao sentido então corrente de cervo enamorado ou amante -, da mesma forma que o faz em outra cantiga do mesmo jogral, em que acusa a filha de "mentir por amigo" para justificar o fato de ter-se demorado na fonte. ${ }^{61}$

\footnotetext{
${ }^{59}$ AZEVEDO FILHO, 1974, p. 47.

${ }^{60}$ CUNHA, 1985, p. 30.

${ }^{61}$ AZEVEDO FILHO, 1974, p. 79.
} 
Mas, deixada de lado tal interpretação 'literal', podemos estabelecer uma exegese alegórica e mesmo anagógica das imagens do cervo e da fonte. Nesta, o cervo remete ao Cristo e a enamorada à alma "que, depois de superar empecilhos vários para liberar-se dos pecados, purificada com a água [da fonte], acaba por atender ao seu [do cervo-Cristo] apelo". ${ }^{62}$

Enfim, "o irresistível bramar, rouco e selvagem, do cervo a chamar uma companheira tem sido comparado, desde tempos antigos, ao Cristo a invocar a alma-esposa, e a alma esposa a buscá-lo" ${ }^{63}$ Lembra Cunha que Chevalier e Gheerbrant, ${ }^{64}$ que se referem à "esposa" no sentido etimológico de "a prometida", "a noiva", ainda apontam para o significado do cervo como a própria alma: "O cervo simboliza tanto o Esposodivino, sempre pronto e infatigável no encalço das almas, suas esposas, como a própria alma em busca da fonte divina onde se desalterar".

\section{Considerações finais}

Vimos que o jardim literário do medievo - denominado vergel, horto ou bosque -, se configura, nos exemplares de prosa doutrinária analisados, como meio de consolo, de abastecimento, de cura ou preparação, na vida terrena, para o Paraíso celestial. E que, mesmo na poesia aparentemente descompromissada com este ideal, as imagens recorrentes na literatura de edificação, como de resto na iconografia medieval, aí se fazem presentes, como as do cervo e da fonte magistralmente utlizadas por Pero Meogo em suas cantigas. Isto permite-lhes exegeses que lhes indicam um sentido espiritual ou anagógico.

\footnotetext{
${ }^{62}$ CUNHA, 1985, p. 31.

${ }^{63}$ CUNHA, 1985, p. 31.

${ }^{64}$ CHEVALIER, GHEERBRANT, 1922, p. 225-6.
} 
Vimos também que denominações recorrentes aproximam o jardim dos poetas ao dos doutrinadores religiosos. A 'amiga fremosa' dos trovadores é, em obras como o Bosco deleitoso, a 'esposa', também chamada de 'poomba'; e tais denominações se referem à alma que, nesta obra, se compara aos cervos à busca da fonte para dessedentarem-se. Confessa a alma do pecador arrependido que abraçou a vida solitária, já preparada e ansiando pela Vida eterna, que, "assi como deseja o cervo as fontes das águas, assi desejo a ti, meu Senhor Deus. Grande sede e grande desejo heide ti, senhor Deus, fonte viva". ${ }^{65}$

Portanto, retoma-se a comparação da alma sedenta à cerva que busca a fonte para não morrer, que já víramos estar presente no Salmo 41 (ou 42). ${ }^{66} \mathrm{E}$ o Cristo, a 'fonte de água viva', apresenta-se como ponto de confluência no jardim místico do medievo, do qual percorremos algumas sendas, mesmo que de forma não conclusiva.

\section{Referências}

AFONSO X. Cantigas de Santa Maria. Ed. crít. de Walter Mettmann. 2 vols, Vigo: Edicións Xerais de Galicia, 1981.

ASENSIO, Eugenio. Poética y realidad em el cancionero peninsular de la Edad Media. 2. ed. Madrid: Gredos, 1970.

AZEVEDO FILHO, Leodegário de. As cantigas de Pero Meogo. Estabelecimento crítico dos textos, análise literária, glossário e reprodução facsimilar dos manuscritos. Rio de Janeiro: Gernasa, 1974.

BOOSCO DELEITOSO. Edição, introdução e glossário de Augusto Magne. Vol. I - texto crítico. Rio de Janeiro: [s. n.], 1950.

65 BOSCO, 1950, p. 339.

${ }^{66} \mathrm{Na}$ edição que utilizamos é o 42 (BÍBLIA, [1981], p. 690). 
BÍBLIA DE JERUSALÉM (A). S. Paulo: Edições Paulinas, [1981]. Trad. La Sainte Bible, ed. de 1973.

CORREIA, João David Pinto. Bosco Deleitoso (vb). In: LANCIANI, Giulia; TAVANI, Giuseppe. Dicionário da literatura medieval galega e portuguesa. Lisboa: Caminho, 1993.

CUNHA, Celso Ferreira da. Significância e movência na poesia trovadoresca. Questões de crítica textual. Rio de Janeiro: Tempo Brasileiro, 1985.

DIAS, André (Mestre). Laudes e cantigas espirituais. Escritas aos mil quatrocentos e trinta e cinco anos. Coligidas, anotadas e comentadas por Mário Martins, S. J. Dadas à estampa pelo Mosteiro de Songeverga em Roriz, Negrelos. Lisboa: S. Vicente de Fora, 1951.

GRANDE ENCICLOPÉDIA LARROUSSE CULTURAL. 24 vols. São Paulo: Nova Cultural Ltda., 1998.

GREGORY, Tullio. Natureza (vb). In: LE GOFF, Jacques; SCHMITT, Jean-Claude (Org.). Dicionário temático do Ocidente medieval. Tradução coordenada por Hilário Franco Júnior. Bauru, SP: EDUSC; São Paulo, SP: Imprensa Oficial do Estado, 2002. 2 vol., vol. II, p. 263-277.

HORTO DO ESPOSO. Edição crítica de Irene Freire Nunes com a colaboração de Margarida Santos Alpalhão, Paulo Alexandre Pereira e Joaquim Segura. Estudos introdutórios de Ana Paiva Morais e Paulo Alexandre Pereira. Coordenação de Helder Godinho. Lisboa: Edições Colibri, 2007.

KRAMER, Heinrich; SPRENGER, James. O martelo das feiticeiras Malleus Maleficarum. Trad. Paulo Fróes. 2. ed., Rio de Janeiro: Rosa dos Tempos, 1991. p. 114.

LE GOFF, Jacques. A bolsa e a vida. São Paulo: Brasiliense, 1989.

MAGNE, Augusto. Boosco deleitoso. Edição, introdução e glossário. Vol. I - texto crítico. Rio de Janeiro: [s.n.], 1950.

MALEVAL, Maria do Amparo Tavares. Rastros de Eva no imaginário ibérico. Santiago de Compostela: Laiovento, 1995. 
MARTINS, Mário. Boosco deleitoso. In: COELHO, Jacinto do Prado (Diretor). Dicionário de literatura, vol. I. 3. ed. Porto: 1973.

MARTINS, Mário. O Vergel de Consolação. Separata da Revista Brotéria. Lisboa, 1949. Reeditado em Estudos de literatura medieval. Braga: [s. n.], 1956, p. 191 e ss.

MÉNDEZ FERRÍN. O cancioneiro de Pero Meogo. Vigo: Galaxia, 1966.

ORTO DO ESPOSO. Edição crítica de Bertil Maler. Vol. I. Rio de Janeiro: MEC/INL, 1956.

PICCHIO, Luciana Stegagno. Corpus de poesia mozárabe. Barcelona: HISPAM, 1973.

VIRGEU DE CONSOLAÇON. Edição de Albino de Bem Veiga, com introdução, gramática, notas e glossário. Salvador: Universidade da Bahia / Livraria do Globo, 1959. 


\section{Resumo}

Reflexões sobre a concepção de jardim em obras de doutrinação religiosa procedentes da Baixa Idade Média portuguesa, observando-lhes os lugares-comuns na representação da natureza enquanto Livro também divino, como a Bíblia. Comparação com a poesia profana galegoportuguesa, que também se utiliza de imagens recorrentes na prosa de edificação, apontando para seu possível sentido anagógico.

\section{Résumé}

On présente ici quelques réflexions à propos du jardin dans des ouvrages de doctrine religieuse du Bas Moyen Âge portugais, en essayant d'y observer les lieux communs dans la réprésentation de la nature en tant que Livre divin comme la Bible. On compare aussi la poésie profane galicienne portugaise laquelle s'utilise des images récurrents dans la prose édifiante, en y pointant leur possible sens anagogique. 